\title{
The sources of volatility transmission in the Euro area money market: from longer maturities to the overnight?
}

\author{
Paolo Zagaglia*
}

May 15, 2008

\begin{abstract}
This note investigates the transmission of volatility from longer maturities to the overnight segment of the Euro area money market. I use non-parametric estimates of the daily variance of swap rates to test for block exogeneity with respect to the overnight. The results suggest that there exists transmission of volatility shocks from the 1-year swap rate to the overnight market. The reform of the operational framework of March 2004 has improved the segmentation of the market, as it has insulated the overnight segment from spillovers in volatility stemming from swap rates up to 6 months of maturity.
\end{abstract}

KEYWORDS: money market, high-frequency data, Granger causality

JEL Classification: C22, E58.

\section{Introduction}

The overnight segment of the Euro area money market plays a special role in the monetary transmission mechanism of monetary policy. ECB (2006) argues that it is crucial for the volatility of the overnight rate to stay low. The reason is that the overnight interest rate signals the stance of monetary policy. Hence it should stand close to the key policy rate. On March 10 2004, a number of changes to the operational framework of monetary policy were implemented to prevent excessive money-market volatility from taking place during the weekly main refinancing operations of the European Central Bank. ${ }^{1}$

The core principle of the conduct of the liquidity policy of the ECB is that of neutrality. ECB (2005b) suggests that the monetary-policy stance should be affected only by the decision on the key interest rates, and should not be impaired by the management of the daily liquidity conditions. Cassola and Morana (2006) and Durré and Nardelli (2007) use non-parametric estimates of the daily realized volatility of money-market swaps to study the transmission of shocks along the maturity

\footnotetext{
*Zagaglia: Stockholm University, pzaga@ne.su.se. I am deeply grateful to Stefano Nardelli for all his support, and to workshop participants at the ECB (in particular Tobias Linzert and Diego Rodriguez-Palenzuela) for their thought-provoking comments. This paper was written during an internship at the Monetary Policy Stance Division of the ECB provided, whose kind hospitality is acknowledged.

${ }^{1} \mathrm{ECB}(2005 \mathrm{a}, 2006)$ show that these modifications have stabilized the volatility of the overnight interest rate.
} 
structure of the money market. Durré and Nardelli (2007) find that there are no statisticallysignificant volatility spillovers arising from the overnight segment onto longer maturities

This note investigates a different channel of volatility interactions by focusing on the transmission of shocks from the longer maturities to the overnight money market. The presence of spillovers from long maturities to the overnight has not been investigated previously. However, this is a relevant issue because it concerns the determination of the volatility of the overnight rate.

I employ updated estimates of the measure of realized volatility of Durré and Nardelli (2007) to test for block exogeneity and Granger causality from the longer maturities to the overnight rate. This amounts to testing whether the past information from the swap rates of longer maturities help to predict the overnight rate.

The results provide evidence in favor of a transmission channel of volatility from the longer end of the money-market swap curve, namely the 1-year swap rate, to the overnight market. This finding is robust to the changes of the operational framework of 2004. Furthermore, the reform has improved the segmentation of the market, as it has insulated the overnight segment from spillovers in volatility stemming from swap rates up to 6 months of maturity.

\section{Results}

Our dataset consists of daily nonparametric estimates of realized volatility spanning from November 112000 to July 10 2007, for a total of 1719 observations. The nonparametric volatilities are computed from tick-by-tick data sampled at a 5 -minute frequency. ${ }^{2}$

The tests for weak block exogeneity are along the lines of Sims (1980). I consider a multivariate VAR model with the overnight rate and money-market swap rates of maturity of one, three, six months and one year. Let the vector $x_{t}=\left[\begin{array}{lllll}o n & 1 m & 3 m & 6 m & 1 y\end{array}\right]^{\prime}$ collect the endogenous variables. The reduced-form vector-autoregression of order $q$ is

$$
x_{t}=k+\sum_{i=1}^{q} B_{i} x_{t-i}+C e_{t}+u_{t}
$$

The vector $e_{t}$ contains three exogenous variables related to the deterministic seasonal functioning of the money market. The first variables takes the value 1 for the six days before the end of the maintenance period, and zero otherwise. The second variable assigns the value 1 to the days between the last main refinancing operation and the end of the maintenance period. Finally, in order to account for calendar effects, an additional dummy is included with the value 1 for the last business day of each month.

Assume that there is no transmission of shocks from the block of yields at 6 months and 1 year

\footnotetext{
${ }^{2}$ The dataset was kindly provided by Stefano Nardelli.
} 
to the rest of the system. This can be formalized as a zero restriction

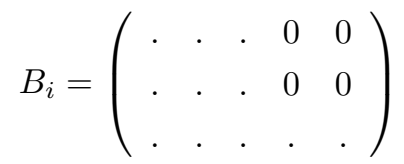

for $i=1, \ldots m$. Block exogeneity of 6 -month and 1-year rates tests if 2 holds. This amounts to estimating an unrestricted VAR, where all the rates enter the system, and a restricted VAR, which excludes the maturities longer than the overnight. Given the variance-covariance matrix $\Omega_{U}$ of the unrestricted model, and the variance-covariance matrix $\Omega_{R}$ of the restricted model, the likelihood-ratio test statistics $L R$ can be computed

$$
L R=(T-p)\left(\log \left|\Omega_{R}\right|-\log \left|\Omega_{U}\right|\right),
$$

where $T$ is the number of observations, $p$ indicates the number of parameters of the unrestricted system, and $|\Omega|$ denotes the determinant of $\Omega$. The null hypothesis is that the estimated coefficients of the block of restricted variables does not enter remaining part of the system in a statistically significant way. The test statistics is asymptotically distributed as a $\chi^{2}$ with degrees of freedom equal to the number of restrictions in the system.

One preliminary aspect is relevant when testing for block exogeneity, namely the fact that the asymptotic distribution of the test statistic is sensitive to the presence of unit roots (see Watson, 1994). Hence I test for unit roots using the modifications of the statistics of Dickey and Fuller (1979) and Phillips and Perron (1988) proposed by Perron and Ng (1996, 2001). These statistics correct for the large distortions arising from the presence of near-unit roots and outliers. Table 1 shows that the null of a unit root is rejected for all the test statistics. As a result, the VAR models are estimated in levels.

Table 2 reports the results of the block-exogeneity tests for the subsamples before and after the reform of the operational framework of March 10 2004. The first row of table 2 tests the restriction that the coefficients on the lags of the maturities longer than the overnight are zero. The zero $p$-values indicate that the information from the swap curve has predictive power for the overnight rate. The same consideration holds also when the the restrictions are on vectors with swap rates at the longer end of the term structure. This raises the question of which rate contributes to the presence of volatility spillovers from the longer end to the overnight of the money market curve.

Tables 3 reports the Wald test statistics on the lags of the swap rates for the first equation of the VAR model 1. The Wald tests reject the null for at least one rate in each subsample when the overnight rate is the dependent variable. This explains the rejection of the null of exogeneity of the block of swap rates from table 2. However, the Wald tests do not keep into account the interactions between the lags of the swap rates, nor their impact on the overnight.

To give a better account for the sources of segmentation of the money market, tables 4 reports the results of system-wide tests for Granger causality with respect to the equation of the overnight rate. These are $F$ tests on each swap rate. The key result is that the reform of the operational 
framework of March 2004 has changed considerably the pattern of interactions between the volatility of longer-term swap and overnight rates. Before the reform, there is evidence of spillovers in volatility from all the swap rates to the overnight segment. This no longer holds after the reform, that has insulated the overnight segment from movements in the volatility of the swap rates with maturity of up to 6 months. The increase in segmentation between the overnight and the rest of the money market induced by the 2004 reform can explain the reduction in the volatility of the overnight rate discussed in the ECB (2005a, 2006). However, the reform has had no impact on the interaction channel running from the 1-year swap to the overnight rate.

\section{Conclusion}

This note studies the segmentation of the Euro-area money market. Two results are proposed. First, there is evidence of a transmission channel of volatility shocks between the 1-year swap and the overnight rate. This finding stresses that anchoring the expectations about the policy stance can indirectly yield benefits of stability in the overnight segment through money market linkages. Secondly, the note shows that the 2004 reform of the operational framework for the liquidity policy of the ECB has improved the segmentation of the market by insulating the overnight segment from volatility shocks to swap rates with maturity of up to 6 months.

\section{References}

Andersen, Torben, Tim Bollerslev, and Francis Diebold, "Parametric and Nonparametric Mesurement", NBER Working Paper, No. 279, 2002

Cassola, Nuno, and Claudio Morana, "Comovements in Volatility in the Euro Money Market", ECB Working Paper, No. 703, 2006

Dickey, D. A., and W. A. Fuller, "Distribution of the Estimators for Autoregressive Time Series with a Unit Root", Journal of the American Statistical Association, 74, 1979

Durré, Alain, and Stefano Nardelli, "Volatility in the Euro Area Money Market: Effects from the Monetary Policy Operational Framework", forthcoming in International Journal of Economics and Finance, December 2007

European Central Bank, "The Volatility of the Overnight Interest Rate from a Medium-Term Perspective", Monthly Bulletin, March 2005, 25-27

European Central Bank, "The Transmission of Overnight Interest Rate Volatility to Longer-Term Interest Rates in the Euro Area Money Market", Monthly Bulletin, August 2005, 24-26

European Central Bank, "The Eurosystem's Operational Framework and the Volatility of the Overnight Interest Rate", Monthly Bulletin, July 2006, 24-29 
European Central Bank, "Volatility of the Overnight Interest Rate and its Transmission along the Money Market Yield Curve", Monthly Bulletin, August 2006, 26-29

Perron, P., and S. Ng, "Useful Modifications to Unit Root Tests with Dependent Errors and Their Local Asymptotic Properties", Review of Economic Studies, 63, 1996

Perron, P., and S. Ng, "Lag Length Selection and the Construction of Unit Root Tests with Good Size and Power", Econometrica, 69, 2001

Phillips, P. C. B., and P. Perron, "Testing for a Unit Root in Time Series Regression", Biometrika, 75,1988

Sims, Christopher A., "Macroeconomics and Reality", Econometrica, 48, 1-48

Watson, Mark (1994), "Vector Autoregressions and Cointegration," in Handbook of Econometrics, R. F. Engle and D. L. McFadden, Elsevier, 2843-2915. 
Table 1: Unit-root tests

Before 10 March 2004 After 10 March 2004

\begin{tabular}{lll} 
& \multicolumn{2}{c}{ Overnight rate } \\
\cline { 2 - 3 }$M Z_{\alpha}$ & $-14.2072^{*}$ & $-17.5419^{*}$ \\
$M Z_{t}$ & $-2.7953^{*}$ & $-2.9354^{*}$ \\
$\mathrm{ADF}$ & $-2.8772^{*}$ & $-3.4421^{*}$ \\
\hline
\end{tabular}

\begin{tabular}{lll} 
& \multicolumn{2}{c}{ 1-month rate } \\
\cline { 2 - 3 }$M Z_{\alpha}$ & $-31.6747^{*}$ & $-19.0730^{*}$ \\
$M Z_{t}$ & $-3.9765^{*}$ & $-3.0877^{*}$ \\
$\mathrm{ADF}$ & $-4.6843^{*}$ & $-3.5130^{*}$ \\
\hline
\end{tabular}

\begin{tabular}{lll} 
& \multicolumn{2}{c}{ 3-month rate } \\
\cline { 2 - 3 }$M Z_{\alpha}$ & $-17.5208^{*}$ & $-16.8233^{*}$ \\
$M Z_{t}$ & $-2.9019^{*}$ & $-2.4313^{* *}$ \\
$\mathrm{ADF}$ & $-2.7500^{*}$ & $-2.9226^{*}$ \\
\hline
\end{tabular}

\begin{tabular}{lll} 
& \multicolumn{2}{c}{6 -month rate } \\
\cline { 2 - 2 }$M Z_{\alpha}$ & $-27.5612^{*}$ & $-14.2620^{*}$ \\
$M Z_{t}$ & $-3.6858^{*}$ & $-2.5558^{* *}$ \\
$\mathrm{ADF}$ & $-4.4074^{*}$ & $-2.7168^{*}$ \\
\hline
\end{tabular}

\begin{tabular}{lll} 
& \multicolumn{2}{c}{ 1-year rate } \\
\cline { 2 - 3 }$M Z_{\alpha}$ & $-19.7056^{*}$ & $-15.9491^{*}$ \\
$M Z_{t}$ & $-3.0329^{*}$ & $-2.3721^{* *}$ \\
$\mathrm{ADF}$ & $-3.9358^{*}$ & $-2.6050^{*}$
\end{tabular}

Legend: The autoregressive models include both a constant and a linear trend. Their order is chosen through the MAIC. The data are GLS-detrended for the estimation of the spectal matrix at zero frequency. $(*)$ rejection at the $1 \%$ level. $(* *)$ rejection at the $5 \%$ level. $(* * *)$ rejection at the $10 \%$ level. 
Table 2: Block-exogeneity LR tests

\begin{tabular}{|c|c|c|}
\hline Restrictions & Before 10 March 2004 & After 10 March 2004 \\
\hline$[m 1, m 3, m 6, y 1]$ & $\underset{(0.0)}{105.4512}$ & $\begin{array}{l}36.6532 \\
(2.1 e-8)\end{array}$ \\
\hline$[m 3, m 6, y 1]$ & $\begin{array}{c}169.9384 \\
(0.0)\end{array}$ & $\underset{(0.0)}{212.0148}$ \\
\hline$[m 6, y 1]$ & $\begin{array}{c}135.7874 \\
(0.0)\end{array}$ & $\begin{array}{c}184.3802 \\
(0.0)\end{array}$ \\
\hline
\end{tabular}

Legend: This table reports the test statistics and the $p$-values (in brackets) from the tests of block exogeneity. The tests are computed on Vector Autoregressions on daily data for realized volatility. The orders of the VARs are selected through the Bayesian-Schwartz criterion. The variables read as: on realized volatility on the overnight, $1 \mathrm{~m}$ realized volatility on the 1 month swap rate, $3 m$ realized volatility on the 3 -month swap rate, $6 m$ realized volatility on the 6 -month swap rate, $1 y$ realized volatility on the 1 -year swap rate. 
Table 3: Block-exogeneity Wald tests, on as a dependent variable

\begin{tabular}{|c|c|c|}
\hline Restrictions & Before 10 March 2004 & After 10 March 2004 \\
\hline $1 y$ & $\begin{array}{l}4.7054 \\
(0.1947)\end{array}$ & $\begin{array}{l}8.8683 \\
(0.0119)\end{array}$ \\
\hline $6 m$ & $\begin{array}{l}4.9935 \\
(0.1723)\end{array}$ & $\begin{array}{l}0.6659 \\
(0.7168)\end{array}$ \\
\hline $3 m$ & $\begin{array}{l}7.6719 \\
(0.0533)\end{array}$ & $\begin{array}{l}1.7105 \\
(0.4252)\end{array}$ \\
\hline $1 m$ & $\begin{array}{c}18.0739 \\
(0.0004)\end{array}$ & $\begin{array}{l}6.0157 \\
(0.0494)\end{array}$ \\
\hline
\end{tabular}

Legend: The tests are computed on the first equation of a Vector Autoregression on daily data for realized volatility. The table reports $\chi^{2}$ test statistics and $p$-values (in brackets). 
Table 4: Granger-causality tests on the overnight rate

\begin{tabular}{|c|c|c|c|c|}
\hline & $1 y$ & $6 m$ & $3 m$ & $1 m$ \\
\hline & \multicolumn{4}{|c|}{ does not Granger-cause on } \\
\hline Before 10 March 2004 & $\begin{array}{c}2.30883 \\
(0.075)\end{array}$ & $\begin{array}{c}0.3513 \\
(5 e-7)\end{array}$ & $\begin{array}{l}4.5280 \\
(0.004)\end{array}$ & $\begin{array}{l}9.8861 \\
(2 e-6)\end{array}$ \\
\hline After 10 March 2004 & $\begin{array}{l}2.8770 \\
(0.0568)\end{array}$ & $\begin{array}{l}0.1978 \\
(0.8205)\end{array}$ & $\begin{array}{l}1.2202 \\
(0.2957)\end{array}$ & $\begin{array}{l}0.8322 \\
(0.4354)\end{array}$ \\
\hline
\end{tabular}

Legend: The tests are computed on a VAR of order 2 with daily data for realized volatility. The table reports $F$ test statistics and $p$-values (in brackets). 